\title{
A comparative analysis of the complete chloroplast genomes of three Chrysanthemum boreale strains
}

\author{
Swati Tyagi $^{1}{ }^{\text {, Jae-A Jung }}{ }^{2}$, Jung Sun Kim ${ }^{1}$, So Youn Won ${ }^{\text {Corresp. } 1}$ \\ ${ }^{1}$ Genomics Division, National Institute of Agricultural Sciences, Rural Development Administration, Jeonju, Republic of Korea \\ ${ }^{2}$ Floriculture Research Division, National Institute of Horticultural and Herbal Science, Rural Development Administration, Wanju, Republic of Korea \\ Corresponding Author: So Youn Won \\ Email address: soyounwon@korea.kr
}

Background. Chrysanthemum boreale Makino (Anthemideae, Asteraceae) is a plant of economic, ornamental, and medicinal importance. We characterized and compared the chloroplast genomes of three $C$. boreale strains. These were collected from different geographic regions of Korea and varied in floral morphology.

Methods. The chloroplast genomes were obtained by next-generation sequencing techniques, assembled de novo, annotated, and compared with one another. Phylogenetic analysis placed them within the Anthemideae tribe.

Results. The sizes of the complete chloroplast genomes of the $C$. boreale strains were 151,012 bp (strain 121002), 151,098 bp (strain IT232531), and 151,010 bp (strain IT301358). Each genome contained 80 unique protein-coding genes, 4 rRNA genes, and 29 tRNA genes. Comparative analyses revealed a high degree of conservation in the overall sequence, gene content, gene order, and GC content among the strains. We identified 298 single nucleotide polymorphisms (SNPs) and 106 insertions/deletions (indels) in the chloroplast genomes. These variations were more abundant in non-coding regions than in coding regions. Long dispersed repeats and simple sequence repeats were present in both coding and noncoding regions, with greater frequency in the latter. Regardless of their location, these repeats can be used for molecular marker development. Phylogenetic analysis revealed the evolutionary relationship of the species in the Anthemideae tribe. The three complete chloroplast genomes will be valuable genetic resources for studying the population genetics and evolutionary relationships of Asteraceae species. 
2 A Comparative Analysis of the Complete Chloroplast

3 Genomes of Three Chrysanthemum boreale Strains

4

5

6

7

8

Swati Tyagi ${ }^{1}$, Jae-A Jung ${ }^{2}$, Jung Sun Kim ${ }^{1}$, and So Youn Won ${ }^{1}$

${ }^{1}$ Genomics Division, National Institute of Agricultural Sciences, Rural Development Administration, Jeonju, 54874, Republic of Korea

${ }^{2}$ Floriculture Research Division, National Institute of Horticultural and Herbal Science, Rural Development Administration, Wanju 55365, Republic of Korea

Corresponding Author:

So Youn Won

Genomics Division, National Institute of Agricultural Sciences, Rural Development Administration, Jeonju, 54874, Republic of Korea

Email address: soyounwon@korea.kr

\section{Abstract}

Background. Chrysanthemum boreale Makino (Anthemideae, Asteraceae) is a plant of economic, ornamental, and medicinal importance. We characterized and compared the chloroplast genomes of three $C$. boreale strains. These were collected from different geographic regions of Korea and varied in floral morphology.

Methods. The chloroplast genomes were obtained by next-generation sequencing techniques, assembled de novo, annotated, and compared with one another. Phylogenetic analysis placed them within the Anthemideae tribe.

Results. The sizes of the complete chloroplast genomes of the $C$. boreale strains were 151,012 bp (strain 121002), 151,098 bp (strain IT232531), and 151,010 bp (strain IT301358). Each genome contained 80 unique protein-coding genes, 4 rRNA genes, and 29 tRNA genes. Comparative analyses revealed a high degree of conservation in the overall sequence, gene content, gene order, and GC content among the strains. We identified 298 single nucleotide polymorphisms (SNPs) and 106 insertions/deletions (indels) in the chloroplast genomes. These variations were more abundant in non-coding regions than in coding regions. Long dispersed repeats and simple sequence repeats were present in both coding and noncoding regions, with greater frequency in the latter. Regardless of their location, these repeats can be used for molecular marker development. Phylogenetic analysis revealed the evolutionary relationship of the species in the Anthemideae tribe. The three complete chloroplast genomes will be valuable genetic resources for studying the population genetics and evolutionary relationships of Asteraceae species. 


\section{Introduction}

41 The genus Chrysanthemum belongs to the largest Angiosperm family, the Asteraceae (Hirakawa

42

43

44

45

46

47

48

49

50

51

52

53

54

55

56

57

58

59

60

61

62

63

64

65

66

67

68

69

70

71

72

73

74

75

76

77

78

79 et al. 2019). Chrysanthemum species are economically important (Hirakawa et al. 2019). They are valued as cut flowers or potted garden flowers due to the diversity of their morphological traits including color, shape, and size of the flower head, ray florets, and disc florets (Shinoyama et al. 2012; Song et al. 2018). In addition, they are used as medicinal herbs in Korean and Chinese folk medicine (Won et al. 2018) for the treatment of inflammation, asthma, and diarrhea, and as a traditional health food (Han et al. 2019; Sun et al. 2015; Wang et al. 2015). Polyploidy and hybridization events were reported to be responsible for evolution and speciation of Chrysanthemum genus (Liu et al. 2012; Ma et al. 2016; Yang et al. 2006), and Chrysanthemum species exhibit diverse ploidy levels $(2 \mathrm{n}=2 \mathrm{x}=18$ to $2 \mathrm{n}=10 \mathrm{x}=90)$ (Chen et al. 2008). The commercial cultivar Chrysanthemum $\times$ morifolium Ramat. is a hexaploid species and its genetic studies on important traits and breedings are difficult.

Chrysanthemum include around 40 different species native to Eurasia, especially in Korea, China, and Japan (Liu et al. 2012). However, some species and varieties are narrowly distributed in specific habitats (Kondo et al. 2003; Liu et al. 2012). A total of 8 species, 9 subspecies, and 1 variety were reported in Korea (Hoang et al. 2020; Lee 2006). Of particular importance to the present study is a wild relative, Chrysanthemum boreale Makino, which is a diploid species, bears small yellow flowers, and occurs in natural stands in eastern Asia (Hwang et al. 2013; Kim et al. 2014). Comparative transcriptomic analysis revealed that $C$. boreale diverged from $C$. morifolium about 1.7 million years ago (Won et al. 2017). C. boreale is resistant to one of the most destructive fungal diseases, namely white rust caused by Puccinia horiana Henn. (Park et al. 2014), and it has anti-inflammatory and skin-regenerative properties (Kim et al. 2015a; Kim et al. 2010). Several C. boreale strains collected from natural stands in Korea displayed variations in morphology such as leaf shapes and flower head, and in karyotype with the occurrence of aneuploidy (Hoang et al. 2020; Hwang et al. 2013). However, their genetic sequence divergence remains unknown. Currently, work is underway to sequence the nuclear genome of one $C$. boreale strain aiming to facilitate molecular, genetic, and physiological studies on Chrysanthemum. Molecular markers derived from both nuclear and chloroplast (cp) genomes would help reveal the relationships among strains and the genetic position of $C$. boreale in Asteraceae.

The cp genome encodes proteins that are key to photosynthesis and other metabolic processes (Liu et al. 2018b). The uni-parental inheritance of the cp genome (usually maternal in angiosperms and paternal in gymnosperms) and conserved gene content and order has made cp genome a valuable asset for plant phylogenetic and evolutionary studies (Birky Jr 2001; Wu \& Ge 2012). Plant cp genomes are generally between $120 \mathrm{~kb}$ and $160 \mathrm{~kb}$ in length and have a quadripartite circular structure comprising a pair of inverted repeat (IR) regions, a large single copy (LSC) region, and a small single copy (SSC) region (Thode \& Lohmann 2019). Advances in next-generation sequencing techniques have made it much easier to reconstruct the complete cp genome and uncover phylogenetic relationships at various taxonomic levels (Jansen et al. 
80

81

82

83

84

85

86

87

88

89

90

91

92

93

94

95

96

97

98

99

100

101

102

103

104

105

106

107

108

109

110

111

112

113

114

115

116

117

118

119

2007; Moore et al. 2010; Parks et al. 2009). Although the structure of cp genome is generally conserved, variation between species, subspecies, and individuals is present, and includes SNPs, indels, sequence rearrangements, IR expansion, gene loss, and intron retention ( $\mathrm{Li}$ et al. 2018).

The cp genome sequences have helped to elucidate the phylogenetic relationships and evolutionary history of many plant species, including rice (Oryza AA genome), vegetables in the Brassica genus, and conifer tree (Pinus taeda L.) (Asaf et al. 2018; Kim et al. 2018; Kim et al. 2015b).

Here, we analyzed the cp genomes of three morphologically different $C$. boreale strains collected from different geographic regions in Korea. We discovered their phylogenetic relationships to other species in the tribe Anthemideae, including Chrysanthemum species. This study provides useful genomic information for molecular evolutionary and phylogenetic studies of Asteraceae, and genetic resources for breeding and improvement of chrysanthemum.

\section{Materials \& Methods}

Ethics statement

The plant sample used in this study is neither endangered nor protected, and was collected from an area that was not privately owned or protected in any way. No specific permits were required to conduct this study.

\section{Plant materials and sequencing}

Two $C$. boreale strains with morphological differences were collected from different locations (Figure S1) in the Republic of Korea and deposited at the National Agrobiodiversity Center, Rural Development Administration. The strain from Gongju-si, Chungcheongnam-do was labeled IT232531, and the one from Suwon-si, Gyeonggi-do was labeled IT301358. The total DNA was isolated from fresh leaves as previously described (Kim et al. 2006). The quality and quantity of DNA were examined using a Nanodrop 2000 spectrophotometer (Thermo Fisher Scientific, Waltham, MA, USA) and gel electrophoresis (in 0.8\% agarose). Paired-end libraries of 350-bp insert size were constructed using TruSeq DNA PCR-Free kit (Illumina, San Diego, CA, USA) and sequenced with a 101-bp read length by Macrogen (Republic of Korea) using the HiSeq4000 (Illumina, San Diego, CA, USA) according to the manufacturer's instructions.

Another C. boreale strain, labeled 121002, was collected from Jeongeup-si, Jeollabuk-do

(Hwang et al. 2013) and its cp genome was sequenced. Our group had previously submitted this cp genome sequence to NCBI with accession number MG913594 (Won et al. 2018).

\section{Chloroplast genome assembly and annotation}

The complete cp genome was assembled de novo (Kim et al. 2015b). Briefly, raw reads were trimmed using the Trimmomatic program (Bolger et al. 2014), assembled using the clc_assembler in the CLC Genomics Workbench v6.0 (CLC Bio, Denmark). Gaps were filled using Gap Closer (Luo et al. 2012). The resulting contigs were searched for cp-encoding contigs by BLASTN analysis against the cp genome of $C$. boreale strain 121002, and circularized. These 
120 were annotated using the online programs Dual Organellar GenoMe Annotator (DOGMA), 121 cpGAVAS v.2.0, and BLAST (Shi et al. 2019; Wyman et al. 2004). The structure of transfer 122 RNA (tRNA) was predicted using the tRNAscan-SE 1.21 program using the default settings 123 (Schattner et al. 2005). The circular genome map with structural features was generated using the 124 OGDRAW v1.2 program (Lohse et al. 2013). The resulting cp genome sequences of strains 125 IT232531 and IT301358 were deposited in NCBI under the IDs MN909052 and MN913565, 126 respectively.

127

128

129

\section{Chloroplast genome comparison}

130

131

132

133

134

135

136

137

138

139

140

141

142

143

144

145

146

147

148

149

150

151

152

153

154

155

156

157

158

159

The cp genomes of the three $C$. boreale strains were compared using the mVISTA program in the Shuffle-LAGAN mode, using the annotation of strain 121002 as the reference (Frazer et al. 2004). The SNPs and indels in the cp genome were also recorded using DnaSP6.0 (Rozas et al. 2017) and manually verified from the sequence alignment by Clustal Omega (Sievers et al. 2011).

\section{Characterization of repetitive sequences}

Simple sequence repeats (SSRs) were discovered using the online web tool MISA (http://pgrc.ipk-gatersleben.de/misa/) with the following parameters: ten repetitions for mononucleotide motifs, eight for dinucleotide motifs, four for tri- and tetra-nucleotide motifs, and three for penta- and hexa-nucleotide motifs (Beier et al. 2017). Next, four different types of repeats, namely forward $(\mathrm{F})$, palindromic $(\mathrm{P})$, reverse $(\mathrm{R})$, and complement $(\mathrm{C})$ repeats were analyzed using the REPuter program (https://bibiserv.cebitec.uni-bielefeld.de/reputer) with a minimum repeat size of $30 \mathrm{bp}$ and a Hamming distance of 3 (Kurtz et al. 2001). To reduce redundancy, IRb sequence was removed before analysis and repeats detected at the same position were merged into single repeat.

\section{Phylogenetic analysis}

The entire cp genomes and 77 protein-coding sequences shared in cp genomes of species belonging to tribe Anthemideae were used to reconstruct the phylogenetic relationships. Lactuca sativa $\mathrm{L}$. was used as the outgroup. The species and the accession numbers of their cp genomes in NCBI are listed in Table S1. The nucleotide sequences were aligned using Clustal Omega (Sievers et al. 2011). Maximum likelihood (ML) analyses were conducted using the IQ-TREE web server (http://iqtree.cibiv.univie.ac.at) with the best-fit models determined by ModelFinder in the IQ-TREE package (Table S2) and 1000 bootstrap replicates (Hoang et al. 2018; Kalyaanamoorthy et al. 2017; Nguyen et al. 2015). Bayesian inferences (BI) were performed with MrBayes v. 3.2.7 (Ronquist et al. 2012) and the nucleotide substitution models determined by ModelTest-NG (Darriba et al. 2019) (Table S2). The Markov chain Monte Carlo (MCMC) algorithms were run for 10 million generations and sampled every 1000 generations. The first $25 \%$ of trees were discarded as burn-in and the remaining trees were used to build a majority-rule consensus tree with posterior probability (PP) values for each node. The stationary was

Peer) reviewing PDF | (2020:03:46495:2:0:NEW 21 May 2020) 
160 considered to be reached when the average standard deviation of split frequencies remained

161

162

163

164

165

166

167

168

169

170

171

172

173

174

175

176

177

178

179

180

181

182

183

184

185

186

187

188

189

190

191

192

193

194

195

196

197

198

199

below 0.01. The phylogenetic tree was visualized with FigTree v1.4.4

(http://tree.bio.ed.ac.uk/software/figtree/).

\section{Results}

\section{Characterization of chloroplast genomes}

We used NGS techniques to generate approximately $30.2 \mathrm{~Gb}$ and $34.9 \mathrm{~Gb}$ of raw reads from strains IT232531 and IT301358, respectively. We assembled de novo the complete cp genomes of sizes 151,098 bp for IT232531, and 151,010 bp for IT301358 (Table 1). For comparison, we included the previously reported cp genome of $C$. boreale strain 121002 , which was $151,012 \mathrm{bp}$ in size (Won et al. 2018). All the three $C$. boreale strains had a typical quadripartite structure of cp genomes with an LSC, an SSC, and a pair of IR regions (Figure 1). The length of the LSC region was $82,817 \mathrm{bp}, 82,880 \mathrm{bp}$, and $82,788 \mathrm{bp}$ for the strains 121002 , IT232531, and IT301358, respectively. The SSC region measured $18,281 \mathrm{bp}, 18,312 \mathrm{bp}$, and 18,310 bp in the strains 121002, IT232531, and IT301358, respectively. The strains were comparable in terms of the length of the IR regions and the GC content of the LSC, SSC, IR regions and the complete genome (Table 1). The IR regions had a higher GC content than the LSC and SSC regions due to the presence of GC-rich ribosomal RNA (rRNA) genes and tRNA genes in these regions.

The cp genomes of all the strains comprised 113 unique genes. These included 80 protein-coding genes, 29 tRNA genes, and 4 rRNA genes (Table 2). Each strain contained 61 protein-coding genes and 21 tRNA genes in the LSC region, and 11 protein-coding genes and 1 tRNA gene in the SSC region (Figure 1). Three genes (rps 12, rps19 and $y c f l)$ were distributed in both single copy and IR regions. The IR regions contained seven protein-coding genes, seven tRNA genes, and four rRNA genes each. Because the IR regions are duplicates of each other, all genes in these regions were also duplicated.

The cp genomes of $C$. boreale included 16 intron-containing genes (Table 3). The genes $y c f 3$ and $c l p P$ had two introns each, while all other genes contained a single intron. Nine of the introns were identical in length, whereas seven other introns differed in length between $1 \mathrm{bp}$ and $24 \mathrm{bp}$. The intron of the trnK-UUU gene was largest (2,560-2,575 bp) in all the strains and its pairwise length differed between the strains by $7 \mathrm{bp}$ to $15 \mathrm{bp}$. The intron of the $n d h A$ gene in IT232531 was 24 bp and 6 bp longer than that in strains 121002 and IT301358, respectively. In each strain, the rps 12 gene was trans-spliced, with the $5^{\prime}$ end exon located in the LSC region and the duplicated $3^{\prime}$ end exon located in both the IR regions, as previously reported in other plants (Thode \& Lohmann 2019).

Given that the cp genome of $C$. boreale strain 121002 was obtained using PacBio's long reads (Won et al. 2018), we repeated the cp genome assembly of 121002 using Illumina's short reads as conducted for other $C$. boreale strains. The sequence comparison between two $\mathrm{cp}$ genomes obtained using long reads and short reads revealed that there was no SNP detected. Instead, indels were observed at four genomic regions and all of them were associated with homopolymers. Three indels were located in intergenic spacers (IGSs), trnE-UUC_rpoB (18

Peer) reviewing PDF | (2020:03:46495:2:0:NEW 21 May 2020) 
200 thymines in the long-read assemble vs. 17 thymines in the short-read assemble) and psaA $y c f 3$ 201 (16 vs. 15 adenines), and the intron of $r p l 16$ ( 8 vs. 9 cytosines), which didn't change the protein 202 sequences. However, the coding region of $y c f 1$ possessed one indel (13 adenines vs. 14 adenines) 203 (Figure S2), which resulted in 1,036 amino acids (aa) in the original data due to the premature 204 stop codon. However, one-bp insertion generated the $y c f 1$ protein of 1,668 aa, which was more 205 consistent with the other $C$. boreale strains (1,672 aa in IT232531 and 1,673 aa in IT301358). 206 While we used the original cp sequence deposited in NCBI for analyses, in case of $y c f 1$, we used 207 the newly obtained sequences.

208

209

210

211

212

213

214

215

216

217

218

219

220

221

222

223

224

225

226

227

228

229

230

231

232

233

234

235

236

237

238

239

\section{Variation in chloroplast genomes}

The mVISTA-based identity plot indicated conservation in DNA sequence and gene synteny across the whole cp genome, and revealed the regions with increased genetic variation (Figure

2). The gene number, order, and orientation were conserved. There was higher genetic variability in the single copy (LSC and SSC) regions than in the IR regions, and in non-coding regions than in coding regions. Highly diverged regions included the IGSs, trnK-UUU_rps16, trnSGCU_trnC-GCA, trnR-UCU_trnT-GGU, rps4_trnL-UAA, ndhC_trnV-UAC, psbE_petL, rps16_rps3, and trnL-UAG_rpl32, and the introns of trnK-UUU, rps 16, and $n d h A$ (Figure 2). We detected a total of 298 SNPs (Table S3). The LSC region contained a majority of the SNPs (204, accounting for $68.5 \%$ of the SNPs), followed by the SSC region $(75,25.2 \%)$, and the IR regions $(19,6.4 \%)$. The SNPs were more abundant in non-coding regions: 141 were located in intergenic regions, 46 in introns, and 111 in coding regions. The $y c f 1$ gene contained the largest number of substitutions (25 SNPs), followed by the trnK-UUU intron (18 SNPs), rpoC2 (12 SNPs), and the $y c f 1$ rps 15 IGS (11 SNPs).

We detected a total of 106 indels (Table S4): 81 in the LSC, 19 in the SSC, and 6 in the IR regions. A total of 86 and 17 indels were located in IGS and introns, respectively, whereas 3 were contained in coding regions. The $n d h C_{-} \operatorname{trn} V-U A C$ spacer had five indels, while the introns of trnK-UUU and $n d h A$, and the spacers of $p s a A \_y c f 3$ and $p s b E \_p e t L$ contained four indels each. The $p s b E$ pet $L$ IGS included the two largest indels (54 bp and $36 \mathrm{bp}$ ) in the cp genome. The $\operatorname{trnK}$-UUU intron was the longest in the genome, and one of the most variable regions, comprising both SNPs and indels (Figure S3). The 5-bp deletion at the end of the protein-coding gene rpoC2 in strain IT232531 generated a protein that was longer by two amino-acids. In the $y c f 1$ gene, the 3-bp insertion in strain IT301358 did not change the protein's translational frame.

We investigated the position of genes at the junction regions (LSC/IRa, IRa/SSC, $\mathrm{SSC} / \mathrm{IRb}$, and IRb/LSC; Figure 3). At the LSC/IRa junction, C. boreale possessed $r p s 19$ with $220 \mathrm{bp}$ in LSC and $59 \mathrm{bp}$ in IRa. The IRa/SSC junction contained the functional $y c f l$, while the $\mathrm{SSC} / \mathrm{IRb}$ possessed the duplicated partial copy, pseudogene $y c f 1$ (Yycfl) and $n d h F$. At the $\mathrm{IRb} / \mathrm{LSC}$ junction, $r p l 2$ and $t r n H-G U G$ were located within the distance of $122 \mathrm{bp}$ to $124 \mathrm{bp}$ from each other.

\section{Repeat analysis}


240 We investigated the distribution of SSRs that were $1 \mathrm{bp}$ to $6 \mathrm{bp}$ in length in the $C$. boreale $\mathrm{cp}$

241

242

243

244

245

246

247

248

249

250

251

252

253

254

255

256

257

258

259

260

261

262

263

264

265

266

267

268

269

270

271

272

273

274

275

276

277

278

279

genomes. We recorded a total of 47, 43, and 50 SSR motifs in 121002, IT232531, and IT301358, respectively (Table S5). Mononucleotide repetition was most prevalent in each cp genome, followed by tri-, penta-, and tetra-nucleotide repetition (Figure 4A). We did not detect di- or hexa-nucleotide SSRs. In terms of sequence context, there were more adenine and thymine residues than cytosine and guanine residues (Figure 4A). Intergenic and intronic regions contained more SSRs than coding regions, with 41, 37, and 42 instances of SSR occurrence in the non-coding regions in the 121002, IT232531, and IT301358 strains, respectively (Figure 4B). Most of the SSRs were located in the LSC region followed by those in the IR region (Figure 4C).

We detected four different types of long dispersed repeats (LDRs), namely forward (F), palindromic $(\mathrm{P})$, reverse $(\mathrm{R})$, and complement $(\mathrm{C})$ repeats, each with a motif length longer than $30 \mathrm{bp}$. We identified a total of 19 (12F, 5P, 2R), $18(11 \mathrm{~F}, 7 \mathrm{P})$, and 16 (9F, 5P, 1R, 1C) repeats in the cp genomes of strains 121002, IT232531, and IT301358, respectively (Figure 5A, Table S6). $\mathrm{F}$ and $\mathrm{P}$ repeats were more abundant than $\mathrm{C}$ and $\mathrm{R}$ repeats. Repeat units of 30-34 bp were the most common, whereas repeat units longer than $40 \mathrm{bp}$ occurred less frequently (Figure 5A). More LDRs were located in non-coding regions (IGS and introns) than in coding regions (Figure 5B). Among the protein-coding genes, LDRs were detected in the $p s a A, p s a B$, and $y c f 2$ in all three $C$. boreale strains (Table S6). Most LDRs were present in LSC region compared to IR and SSC regions, while some LDRs were shared among LSC, IR, and SSC regions (Figure 5C).

\section{Phylogenetic analysis}

The phylogenetic trees were constructed based on complete cp genome sequences and 77 protein-coding genes that were common to the three $C$. boreale strains, the 17 other species of the tribe Anthemideae (Asteroideae, Astereaceae), and the outgroup species, L. sativa (Cichorieae, Cichorioideae, Asteraceae). The multiple alignment of complete cp genomes contained 158,397 nucleotide sites in which 11,844 were variable and 3,371 were parsimony informative. The multiple alignment of protein-coding sequences possessed 62,965 nucleotide sites in which 3,065 were variable and 900 were parsimony informative. In each cp sequences, both ML and BI trees revealed similar topologies but minor difference within Chrysanthemum species (Figure 6, S4). Two datasets also resulted in similar phylogenetic relationship. All Chrysanthemum sequences were grouped into a single clade together with Opisthopappus taihangensis (Ling) C.Shih with high bootstrap support and Bayesian inference (Figure 6). Three C. boreale strains were all non-monophyletic, which was also observed in two C. morifolium analyzed. Additionally, Artemisia species were clustered into two clades. Among them, seven species formed a monophyletic group, and other three were located in another clade and were closer to the Chrysanthemum clade.

\section{Discussion}

The overall cp genome structures and sequences in the three $C$. boreale strains examined here were conserved and displayed the classical quadripartite structure of land plant $\mathrm{cp}$ genomes

Peer) reviewing PDF | (2020:03:46495:2:0:NEW 21 May 2020) 
280 (Shen et al. 2018). The gene content, gene order, and gene orientation in the cp genomes were

281

282

283

284

285

286

287

288

289

290

291

292

293

294

295

296

297

298

299

300

301

302

303

304

305

306

307

308

309

310

311

312

313

314

315

316

317

318

319

conserved. Genomic rearrangements such as inversion of the SSC or of individual genes is common in cp genomes (Liu et al. 2018a). However, there were no definitive genomic rearrangements or gene inversions in the three $C$. boreale strains. The length differences of $\mathrm{cp}$ genomes were observed among strains, which was due to variation mainly in the lengths of the LSC and SSC regions. The IR region, which influences the evolution of cp genomes due to its expansion, contraction, or complete loss (Wicke et al. 2011; Zhu et al. 2016), was similar in length, with only a $1-4$ bp difference among strains. Our results are consistent with similar studies of the cotton genus (Gossypium), in which the length of LSC regions accounted for the cp genome size difference (Chen et al. 2017). This is different from studies in duckweed species (Lemnoideae), in which differences in cp genome size were due to differences in IR regions (Ding et al. 2017).

Sequence identity plot and the analyses of SNPs and indels revealed the variable regions in the cp genome of $C$. boreale. In line with observations in other plant species, the LSC and SSC regions were more divergent than the IR regions, and non-coding regions were more variable than coding regions (Meng et al. 2019; Wang et al. 2018). Among the variable regions in the C. boreale cp genome, the introns of $\operatorname{trnK}-U U U$ and $n d h A$, and the spacers of $n d h C_{-} \operatorname{trnV}$ $U A C, y c f 1$ rps 15, trnL-UAG_rpl32, and $p s b E \_p e t L$ as well as the coding regions of $y c f 1$ and rpoC2 contained many polymorphisms, suggesting rapid genome evolution due to higher mutation rates than other regions. The trnK-UUU intron was longer than $2.5 \mathrm{~kb}$ and encompassed matK, which included six SNPs. This region has been extensively used as a molecular marker for phylogenetic and evolutionary studies (Hausner et al. 2006). Therefore, future studies investigating phylogeny and evolution in relatives of $C$. boreale are likely to find its cp genome a useful resource.

We also detected variation in the number and distribution of two types of repeats, SSRs and LDRs, in both non-coding (IGS and intron) and coding regions. The occurrence of repeats was more prevalent in the non-coding regions than in the coding regions, similar to reports in other species (Kim et al. 2015b; Meng et al. 2019; Shen et al. 2018). Differential distribution of these repeats is associated with cp genome rearrangement and nucleotide substitution (Weng et al. 2014). Therefore, these repeats could be used to develop genetic markers for phylogenetic studies. The obtained SSR repeats, together with the variable regions could be used to examine the genetic structure, diversity, phylogeny, and differentiation of Chrysanthemum and other Asteraceae species.

The phylogenetic analysis revealed the evolutionary relationships of species in the Anthemideae tribe. The investigated species were clustered into a monophyletic group and were largely classified into two groups: Chrysanthemum and Artemisia. The Chrysanthemum clade included Chrysanthemum species, O. taihangensis, Crossostephium chinense Makino, and unexpected three Artemisia species (A. annua, A. fukudo, and A.maritima), while the Artemisia clade included the remaining seven Artemisia species, which was consistent with the previous analysis (Gu et al. 2019). However, other phylogenetic studies showed that all Artemisia species

Peer) reviewing PDF | (2020:03:46495:2:0:NEW 21 May 2020) 
320

321

322

323

324

325

326

327

328

329

330

331

332

333

334

335

336

337

338

339

340

341

342

343

344

345

346

347

348

349

350

351

352

353

354

\section{5}

356

357

358

359

were clustered together and separated from its sister genus Chrysanthemum (Meng et al. 2019; Shahzadi et al. 2020). In their analyses, the three Artemisia species closer to Chrysanthemum in our study formed a separated clade within the Artemisia genus. At least, it is clear that Artemisia species are classified into two groups based on cp sequences but their relationship with Chrysanthemum needs to be further addressed.

Within the Chrysanthemum clade, $C$. boreale strains were placed in separate branches. Two C. morifolium cultivars from Korea and China were also placed in separate branches. This was similar to an earlier phylogenetic analysis of more diverse Chrysanthemum species that used seven cp regions and a single copy nuclear gene (the chrysanthemyl diphosphate synthase, CDS gene): different strains of $C$. indicum were located in different branches (Liu et al. 2012). On the other hand, we assembled the nuclear genomic regions encompassing the ribosomal RNAs and the nuclear ribosomal internal transcribed spacer (nrITS) of around $5.8 \mathrm{~kb}$ in size for three $C$. boreale strains and C. morifolium cv. Baekma with the same approach for cp genome (Supplementary Data1). Their phylogenetic relationships based on nuclear sequences indicated that all Chrysanthemum sequences formed a monophyletic group in which $C$. boreale strain IT301358 was clustered together with C. morifolium cv. Baekma (Figure S5). These results suggest the close affinity within the Chrysanthemum genus and therefore the classification or circumscription using cp and nrITS sequences would be difficult within Chrysanthemum. Divergence and speciation in the Chrysanthemum genus were suggested to be affected by geographical and ecological factors (Liu et al. 2012). Further research including other cultivars and varieties from different regions, and molecular markers from nucleus genome sequences, may reveal the origin of cultivated chrysanthemum and the genetic relationships within the Chrysanthemum group.

O. taihangensis is a monotypic species in the genus (Gu et al. 2019) and its phylogenetic position as a sister taxon of $C$. boreale was inconsistent with previous studies in which $O$. taihangensis was basal to the Chrysanthemum group when nrITS sequences were used (Zhao et al. 2010). Considering that nrITS sequences can be as short as 447 bp (Zhao et al. 2010), we would expect fewer informative polymorphisms from ITS than the cp as a whole. However, we cannot exclude the possibility that the phylogeny based on the cp genome was sometimes unreliable due to the mode of inheritance of cp genome (Folk et al. 2017; Tonti-Filippini et al. 2017). Hybridization between distant species (or relatives) and the subsequent chloroplast capture have also been suggested to underlie discrepancies between the nuclear and cp genomes and consequently cause differences in phylogenetic analysis. Phylogenetic trees based on cp and nuclear data also showed the incongruence within Chrysanthemum as discussed above.

\section{Conclusions}

Using next-generation sequencing technology, we compared the complete cp genomes of three C. boreale strains. The gene content, gene order, and GC content of all the three cp genomes were conserved. The rapidly evolving divergent regions and repeats we identified could potentially serve as molecular markers in phylogenetic studies. Phylogenetic analyses using other 
360

361

362

363

364

365

366

367

368

369

370

371

372

373

374

375

376

377

378

379

380

381

382

383

384

385

386

387

388

389

390

391

392

393

394

395

396

397

398

399

400

401

402

403

404

Chrysanthemum species and other species within Anthemideae strongly supported the taxonomic status of the strains within the tribe. The data presented here provide insights into the evolutionary relationships among C. boreale strains and other Chrysanthemum species, and will act as a valuable resource for their molecular identification and breeding, as well as for further biological discoveries.

\section{References}

Asaf S, Khan AL, Khan MA, Shahzad R, Kang SM, Al-Harrasi A, Al-Rawahi A, and Lee I-J. 2018. Complete chloroplast genome sequence and comparative analysis of loblolly pine (Pinus taeda L.) with related species. Plos One 13:e0192966.

Beier S, Thiel T, Münch T, Scholz U, and Mascher M. 2017. MISA-web: a web server for microsatellite prediction. Bioinformatics 33:2583-2585.

Birky Jr CW. 2001. The inheritance of genes in mitochondria and chloroplasts: laws, mechanisms, and models. Annual review of genetics 35:125-148.

Bolger AM, Lohse M, and Usadel B. 2014. Trimmomatic: a flexible trimmer for Illumina sequence data. Bioinformatics 30:2114-2120.

Chen F-d, Zhao H-b, Li C, Chen S-m, and Fang W-m. 2008. Advances in cytology and molecular cytogenetics of the genus Dendranthema. JOURNAL-NANJING AGRICULTURAL UNIVERSITY 31:118.

Chen Z, Grover CE, Li P, Wang Y, Nie H, Zhao Y, Wang M, Liu F, Zhou Z, and Wang X. 2017. Molecular evolution of the plastid genome during diversification of the cotton genus. Molecular phylogenetics evolution 112:268-276.

Darriba D, Posada D, Kozlov AM, Stamatakis A, Morel B, and Flouri T. 2019. ModelTest-NG: A New and Scalable Tool for the Selection of DNA and Protein Evolutionary Models. Molecular Biology and Evolution 37:291-294. 10.1093/molbev/msz189 \%J Molecular Biology and Evolution

Ding Y, Fang Y, Guo L, Li Z, He K, Zhao Y, and Zhao H. 2017. Phylogenic study of Lemnoideae (duckweeds) through complete chloroplast genomes for eight accessions. PeerJ 5:e4186.

Folk RA, Mandel JR, and Freudenstein JV. 2017. Ancestral gene flow and parallel organellar genome capture result in extreme phylogenomic discord in a lineage of angiosperms. Systematic biology 66:320-337.

Frazer KA, Pachter L, Poliakov A, Rubin EM, and Dubchak I. 2004. VISTA: computational tools for comparative genomics. Nucleic Acids Research 32:W273-W279.

Gu J, Wei Z, Yue C, Xu X, Zhang T, Zhao Q, Fu S, Yang D, and Zhu S. 2019. The complete chloroplast genome of Opisthopappus taihangensis (Ling) Shih. Mitochondrial DNA Part $B$ 4:1415-1416. 10.1080/23802359.2019.1598791

Han A-R, Nam B, Kim B-R, Lee K-C, Song B-S, Kim SH, Kim J-B, and Jin CH. 2019. Phytochemical composition and antioxidant activities of two different color Chrysanthemum flower teas. Molecules 24:329.

Hausner G, Olson R, Simon D, Johnson I, Sanders ER, Karol KG, McCourt RM, and Zimmerly S. 2006. Origin and evolution of the chloroplast trnK (matK) intron: a model for evolution of group II intron RNA structures. Molecular Biology Evolution 23:380-391.

Hirakawa H, Sumitomo K, Hisamatsu T, Nagano S, Shirasawa K, Higuchi Y, Kusaba M, Koshioka M, Nakano Y, and Yagi M. 2019. De novo whole-genome assembly in 
405

406

407

408

409

410

411

412

413

414

415

416

417

418

419

420

421

422

423

424

425

426

427

428

429

430

431

432

433

434

435

436

437

438

439

440

441

442

443

444

445

446

447

448

449

Chrysanthemum seticuspe, a model species of Chrysanthemums, and its application to genetic and gene discovery analysis. DNA Research 26:195-203.

Hoang DT, Chernomor O, Von Haeseler A, Minh BQ, and Vinh LS. 2018. UFBoot2: improving the ultrafast bootstrap approximation. Molecular Biology Evolution 35:518-522.

Hoang TK, Wang Y, Hwang Y-J, and Lim J-H. 2020. Analysis of the morphological characteristics and karyomorphology of wild Chrysanthemum species in Korea.

Horticulture, Environment, and Biotechnology 61:359-369. 10.1007/s13580-019-00222-9

Hwang Y-J, Younis A, Bok RK, Lim K-B, Eun C-H, Lee J, Sohn S-H, and Kwon S-J. 2013. Karyomorphological Analysis of Wild Chrysanthemum boreale Collected from Four Natural Habitats in Korea. Flower Research Journal 21:182-189.

Jansen RK, Cai Z, Raubeson LA, Daniell H, Depamphilis CW, Leebens-Mack J, Müller KF, Guisinger-Bellian M, Haberle RC, and Hansen AK. 2007. Analysis of 81 genes from 64 plastid genomes resolves relationships in angiosperms and identifies genome-scale evolutionary patterns. Proceedings of the National Academy of Sciences 104:1936919374.

Kalyaanamoorthy S, Minh BQ, Wong TK, von Haeseler A, and Jermiin LS. 2017. ModelFinder: fast model selection for accurate phylogenetic estimates. Nature Methods 14:587.

Kim C-K, Seol Y-J, Perumal S, Lee J, Waminal NE, Jayakodi M, Lee S-C, Jin S, Choi B-S, and Yu Y. 2018. Re-exploration of U's triangle Brassica species based on chloroplast genomes and 45S nrDNA sequences. Scientific Reports 8:1-11.

Kim DY, Won K-J, Yoon M-S, Hwang DI, Yoon SW, Park J-H, Kim B, and Lee HM. 2015 a. Chrysanthemum boreale Makino essential oil induces keratinocyte proliferation and skin regeneration. Natural product research 29:562-564.

Kim JS, Chung TY, King GJ, Jin M, Yang T-J, Jin Y-M, Kim H-I, and Park B-S. 2006. A sequence-tagged linkage map of Brassica rapa. Genetics 174:29-39.

Kim K, Lee S-C, Lee J, Yu Y, Yang K, Choi B-S, Koh H-J, Waminal NE, Choi H-I, and Kim NH. 2015b. Complete chloroplast and ribosomal sequences for 30 accessions elucidate evolution of Oryza AA genome species. Scientific Reports 5.

Kim SJ, Lee CH, Kim J, and Kim KS. 2014. Phylogenetic analysis of Korean native Chrysanthemum species based on morphological characteristics. Scientia Horticulturae 175:278-289.

Kim Y, Sung J, Sung M, Choi Y, Jeong H-S, and Lee J. 2010. Involvement of heme oxygenase-1 in the anti-inflammatory activity of Chrysanthemum boreale Makino extracts on the expression of inducible nitric oxide synthase in RAW264. 7 macrophages. Journal of ethnopharmacology 131:550-554.

Kondo K, Abd El-Twab M, Idesawa R, Kimura S, and Tanaka R. 2003. Genome phylogenetics in Chrysanthemum sensu lato. Plant Genome-Biodiversity Evolution. p 117-200.

Kurtz S, Choudhuri JV, Ohlebusch E, Schleiermacher C, Stoye J, and Giegerich R. 2001. REPuter: the manifold applications of repeat analysis on a genomic scale. Nucleic Acids Research 29:4633-4642.

Lee YN. 2006. New flora of Korea: Kyo-Hak Publ.

Li Y, Zhang J, Li L, Gao L, Xu J, and Yang M. 2018. Structural and comparative analysis of the complete chloroplast genome of Pyrus hopeiensis_- "wild plants with a tiny population"- - and three other Pyrus species. International journal of molecular sciences 19:3262.

Peer] reviewing PDF | (2020:03:46495:2:0:NEW 21 May 2020) 
450

451

452

453

454

455

456

457

458

459

460

461

462

463

464

465

466

467

468

469

470

471

472

473

474

475

476

477

478

479

480

481

482

483

484

485

486

487

488

489

490

491

492

493

494

Liu H, He J, Ding C, Lyu R, Pei L, Cheng J, and Xie L. 2018a. Comparative analysis of complete chloroplast genomes of Anemoclema, Anemone, Pulsatilla, and Hepatica revealing structural variations among genera in tribe Anemoneae (Ranunculaceae). Frontiers in Plant Science 9:1097.

Liu P-L, Wan Q, Guo Y-P, Yang J, and Rao G-Y. 2012. Phylogeny of the Genus Chrysanthemum L.: Evidence from Single-Copy Nuclear Gene and Chloroplast DNA Sequences. Plos One 7:e48970. 10.1371/journal.pone.0048970

Liu X, Zhou B, Yang H, Li Y, Yang Q, Lu Y, and Gao Y. 2018b. Sequencing and analysis of Chrysanthemum carinatum Schousb and Kalimeris indica. The complete chloroplast genomes reveal two inversions and $\mathrm{rbcL}$ as barcoding of the vegetable. Molecules 23:1358.

Lohse M, Drechsel O, Kahlau S, and Bock R. 2013. OrganellarGenomeDRAW - a suite of tools for generating physical maps of plastid and mitochondrial genomes and visualizing expression data sets. Nucleic Acids Research 41:W575-W581.

Luo R, Liu B, Xie Y, Li Z, Huang W, Yuan J, He G, Chen Y, Pan Q, and Liu Y. 2012. SOAPdenovo2: an empirically improved memory-efficient short-read de novo assembler. Gigascience 1:2047-2217X-2041-2018.

Ma Y-P, Chen M-M, Wei J-X, Zhao L, Liu P-L, Dai S-L, and Wen J. 2016. Origin of Chrysanthemum cultivars-Evidence from nuclear low-copy LFY gene sequences. Biochemical Systematics and Ecology 65:129-136.

Meng D, Xiaomei Z, Wenzhen K, and Xu Z. 2019. Detecting useful genetic markers and reconstructing the phylogeny of an important medicinal resource plant, Artemisia selengensis, based on chloroplast genomics. Plos One 14.

Moore MJ, Soltis PS, Bell CD, Burleigh JG, and Soltis DE. 2010. Phylogenetic analysis of 83 plastid genes further resolves the early diversification of eudicots. Proceedings of the National Academy of Sciences 107:4623-4628.

Nguyen L-T, Schmidt HA, Von Haeseler A, and Minh BQ. 2015. IQ-TREE: a fast and effective stochastic algorithm for estimating maximum-likelihood phylogenies. Molecular Biology Evolution 32:268-274.

Park SK, Lim JH, Shin HK, Jung JA, Kwon YS, Kim MS, and Kim KS. 2014. Identification of Chrysanthemum Genetic Resources Resistant to White Rust Caused by Puccinia horiana. Plant Breeding and Biotechnology 2:184-193.

Parks M, Cronn R, and Liston A. 2009. Increasing phylogenetic resolution at low taxonomic levels using massively parallel sequencing of chloroplast genomes. BMC biology 7:84.

Ronquist F, Teslenko M, Van Der Mark P, Ayres DL, Darling A, Höhna S, Larget B, Liu L, Suchard MA, and Huelsenbeck JP. 2012. MrBayes 3.2: efficient Bayesian phylogenetic inference and model choice across a large model space. Systematic biology 61:539-542.

Rozas J, Ferrer-Mata A, Sánchez-DelBarrio JC, Guirao-Rico S, Librado P, Ramos-Onsins SE, and Sánchez-Gracia A. 2017. DnaSP 6: DNA sequence polymorphism analysis of large data sets. Molecular Biology Evolution 34:3299-3302.

Schattner P, Brooks AN, and Lowe TM. 2005. The tRNAscan-SE, snoscan and snoGPS web servers for the detection of tRNAs and snoRNAs. Nucleic Acids Research 33:W686W689.

Shahzadi I, Mehmood F, Ali Z, Ahmed I, and Mirza B. 2020. Chloroplast genome sequences of Artemisia maritima and Artemisia absinthium: Comparative analyses, mutational

Peer) reviewing PDF | (2020:03:46495:2:0:NEW 21 May 2020) 
495

496

497

498

499

500

501

502

503

504

505

506

507

508

509

510

511

512

513

514

515

516

517

518

519

520

521

522

523

524

525

526

527

528

529

530

531

532

533

534

535

536

537

538

539

540

hotspots in genus Artemisia and phylogeny in family Asteraceae. Genomics 112:14541463.

Shen X, Guo S, Yin Y, Zhang J, Yin X, Liang C, Wang Z, Huang B, Liu Y, and Xiao S. 2018. Complete chloroplast genome sequence and phylogenetic analysis of Aster tataricus. Molecules 23:2426.

Shi L, Chen H, Jiang M, Wang L, Wu X, Huang L, and Liu C. 2019. CPGAVAS2, an integrated plastome sequence annotator and analyzer. Nucleic Acids Research 47:W65-W73.

Shinoyama H, Aida R, Ichikawa H, Nomura Y, and Mochizuki A. 2012. Genetic engineering of chrysanthemum (Chrysanthemum morifolium): Current progress and perspectives. Plant Biotechnology 29:323-337. 10.5511/plantbiotechnology.12.0521a

Sievers F, Wilm A, Dineen D, Gibson TJ, Karplus K, Li W, Lopez R, McWilliam H, Remmert M, and Söding J. 2011. Fast, scalable generation of high-quality protein multiple sequence alignments using Clustal Omega. Molecular systems biology 7:539.

Song C, Liu Y, Song A, Dong G, Zhao H, Sun W, Ramakrishnan S, Wang Y, Wang S, and Li T. 2018. The Chrysanthemum nankingense genome provides insights into the evolution and diversification of chrysanthemum flowers and medicinal traits. Molecular Plant 11:14821491.

Sun H, Zhang T, Fan Q, Qi X, Zhang F, Fang W, Jiang J, Chen F, and Chen S. 2015. Identification of floral scent in chrysanthemum cultivars and wild relatives by gas chromatography-mass spectrometry. Molecules 20:5346-5359.

Thode VA, and Lohmann LG. 2019. Comparative chloroplast genomics at low taxonomic levels: a case study using Amphilophium (Bignonieae, Bignoniaceae). Frontiers in Plant Science 10:796.

Tonti-Filippini J, Nevill PG, Dixon K, and Small I. 2017. What can we do with 1000 plastid genomes? The Plant Journal 90:808-818.

Wang J, Li C, Yan C, Zhao X, and Shan S. 2018. A comparative analysis of the complete chloroplast genome sequences of four peanut botanical varieties. PeerJ 6:e5349.

Wang L, Jiang J, Song A, Wang H, Li P, Guan Z, Chen F, and Chen S. 2015. Comparative transcriptome analysis of Chrysanthemum nankingense in response to nitrogen deficiency. Scientia Horticulturae 195:101-107. http://dx.doi.org/10.1016/j.scienta.2015.09.001

Weng M-L, Blazier JC, Govindu M, and Jansen RK. 2014. Reconstruction of the ancestral plastid genome in Geraniaceae reveals a correlation between genome rearrangements, repeats, and nucleotide substitution rates. Molecular Biology Evolution 31:645-659.

Wicke S, Schneeweiss GM, Depamphilis CW, Müller KF, and Quandt D. 2011. The evolution of the plastid chromosome in land plants: gene content, gene order, gene function. Plant molecular biology 76:273-297.

Won SY, Jung J-A, and Kim JS. 2018. The complete chloroplast genome of Chrysanthemum boreale (Asteraceae). Mitochondrial DNA Part B 3:549-550.

Won SY, Kwon S-J, Lee T-H, Jung J-A, Kim JS, Kang S-H, and Sohn S-H. 2017. Comparative transcriptome analysis reveals whole-genome duplications and gene selection patterns in cultivated and wild Chrysanthemum species. Plant molecular biology 95:451-461. $10.1007 / \mathrm{s} 11103-017-0663-\mathrm{z}$

Wu Z-Q, and Ge S. 2012. The phylogeny of the BEP clade in grasses revisited: evidence from the whole-genome sequences of chloroplasts. Molecular phylogenetics evolution 62:573578.

PeerJ reviewing PDF | (2020:03:46495:2:0:NEW 21 May 2020) 
541 Wyman SK, Jansen RK, and Boore JL. 2004. Automatic annotation of organellar genomes with 542 DOGMA. Bioinformatics 20:3252-3255. 10.1093/bioinformatics/bth352

543 Yang WH, Glover BJ, Rao GY, and Yang J. 2006. Molecular evidence for multiple

544 polyploidization and lineage recombination in the Chrysanthemum indicum polyploid

545

546

547

548

549

550

551

552

553 complex (Asteraceae). New Phytologist 171:875-886. 10.1111/j.1469-8137.2006.01779.x

Zhao H-B, Chen F-D, Chen S-M, Wu G-S, and Guo W-M. 2010. Molecular phylogeny of Chrysanthemum, Ajania and its allies (Anthemideae, Asteraceae) as inferred from nuclear ribosomal ITS and chloroplast trnL-F IGS sequences. Plant Systematics and Evolution 284:153-169. 10.1007/s00606-009-0242-0

Zhu A, Guo W, Gupta S, Fan W, and Mower JP. 2016. Evolutionary dynamics of the plastid inverted repeat: the effects of expansion, contraction, and loss on substitution rates. New Phytologist 209:1747-1756. 


\section{Figure 1}

Genome map of Chrysanthemum boreale chloroplast genomes.

Thick lines indicate the extent of the inverted repeat regions, which separate the genome into large and small single copy regions. Genes drawn inside the circle are transcribed clockwise, while those outside of the circle are transcribed counter clockwise. Genes belonging to different functional groups are color coded differently. The dark grey in the inner circle corresponds to the GC content while the light grey corresponds to the AT content. Genes with introns are marked with an asterisk. 


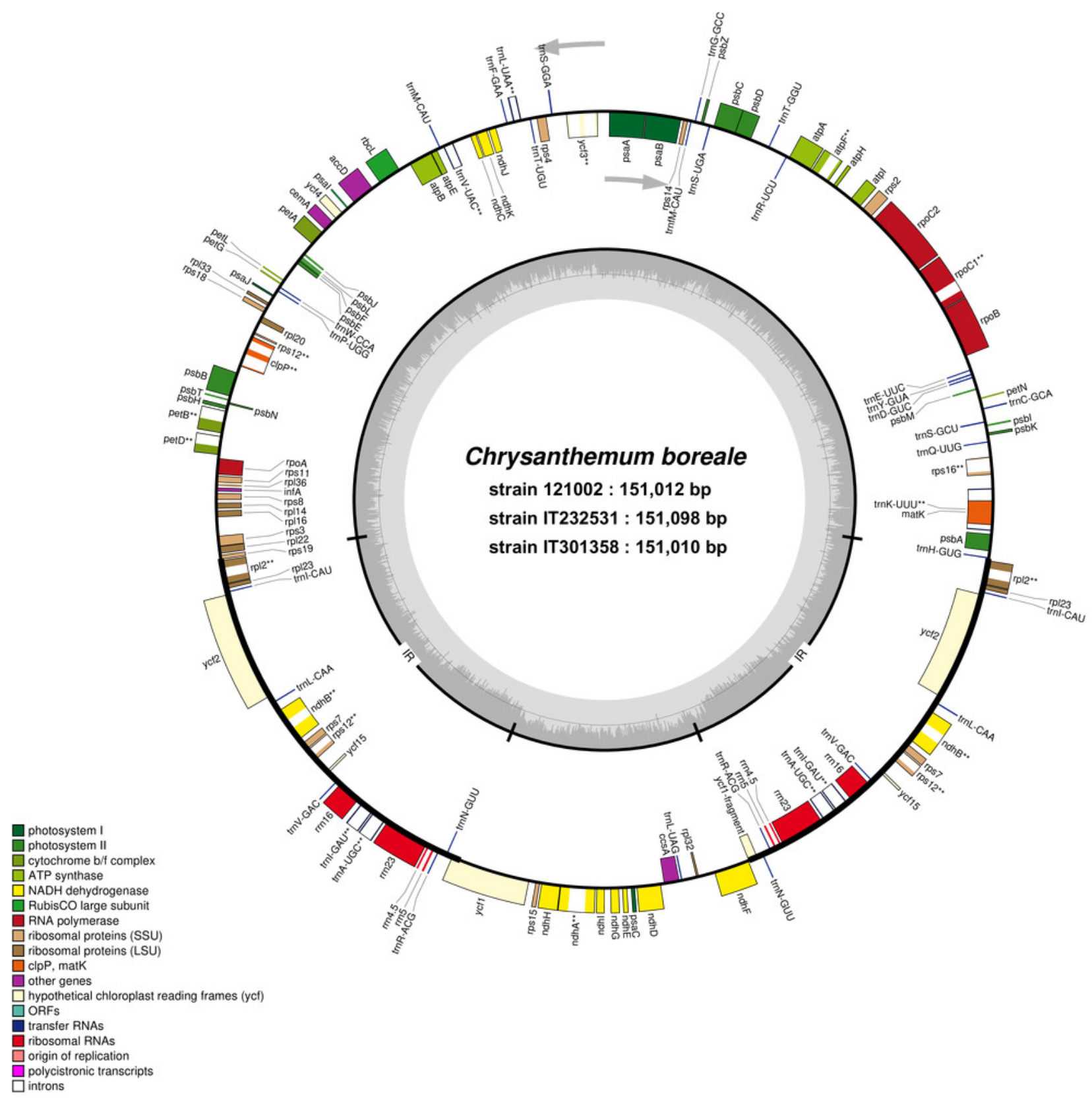


Figure 2

Comparison of chloroplast genomes of $C$. boreale strains using the mVISTA program.

A cut-off of $70 \%$ identity was used for the plots. The Y-scale axis represents the percent identity between $50 \%$ and $100 \%$.

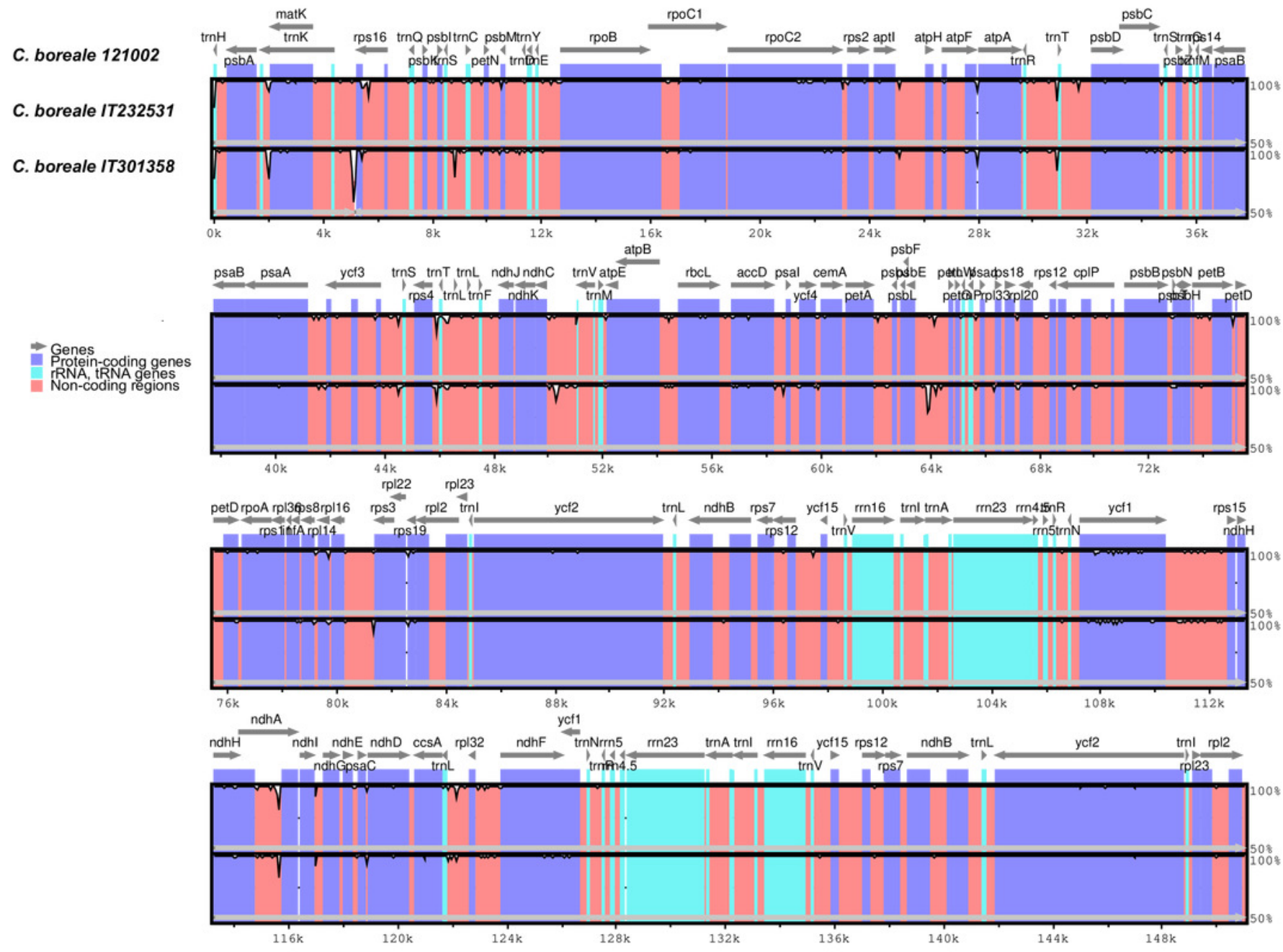


Figure 3

Comparison of the LSC, IR, and SSC junction positions in the chloroplast genomes of the C. boreale strains.

Genes above the longer box are transcribed in forward direction and genes below the box are transcribed in reverse direction. $\Psi$ indicates a pseudogene.

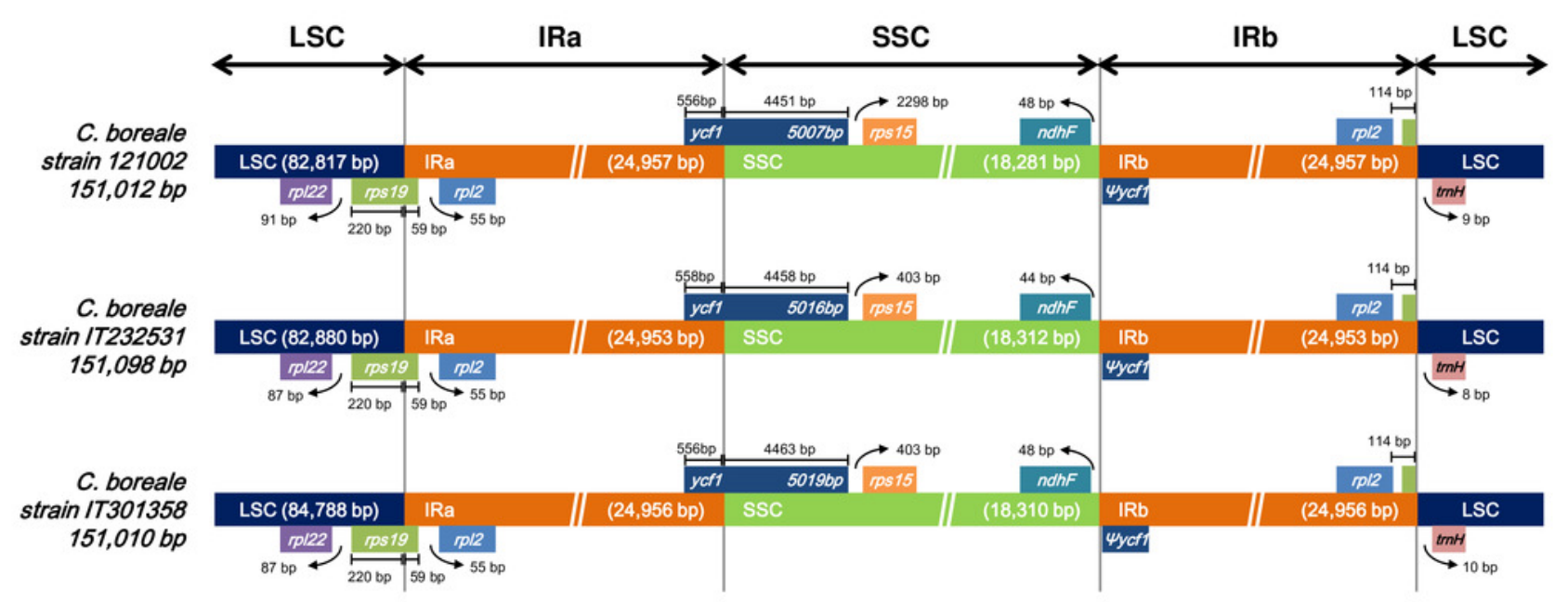


Figure 4

Analyses of simple sequence repeats (SSRs) in C. boreale chloroplast genomes.

(A) The frequency of SSRs per sequence type. (B) The frequency of SSRs in intergenic spacer (IGS), coding sequence (CDS), intron, and IGS/CDS. IGS/CDS represents SSRs shared in IGS and CDS. (C) The frequency of SSRs in large single copy (LSC), inverted repeat (IR), and small single copy (SSC) regions. 


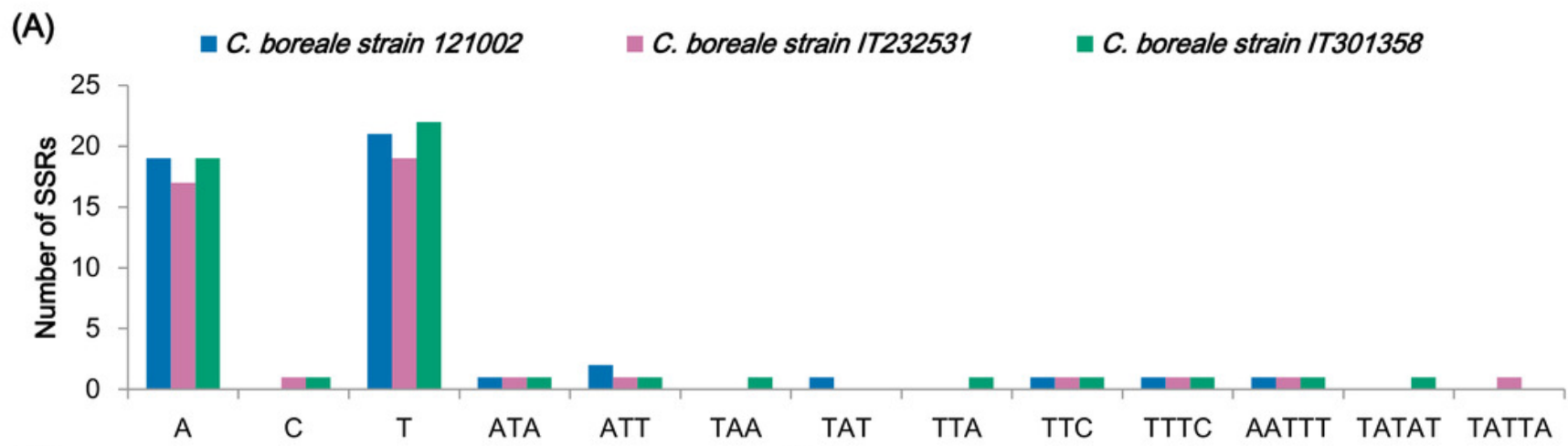

(B)

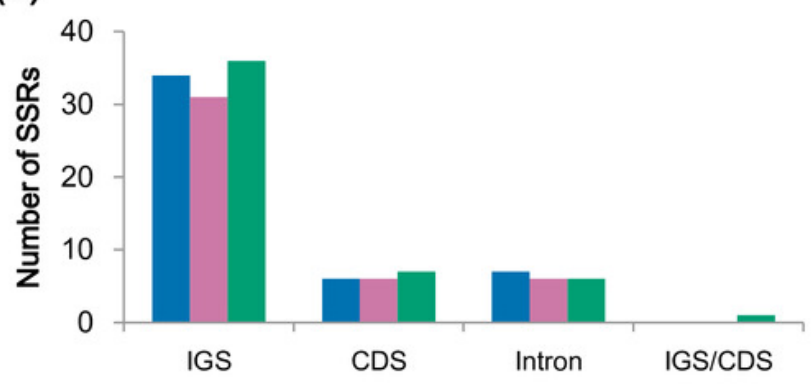

(C)

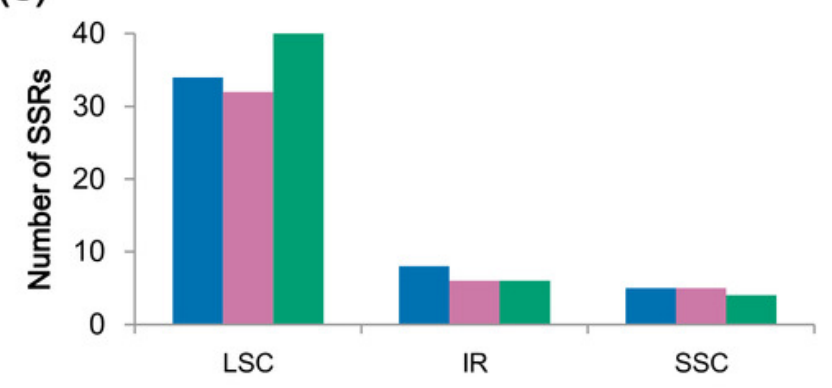




\section{Figure 5}

Analyses of long dispersed repeats (LDRs) in C. boreale chloroplast genomes.

(A) The frequency of LDRs classified by the length and type of repeat: forward (F), palindromic $(P)$, reverse $(R)$, and complement $(C)$ repeats. $(B)$ The frequency of LDRs in intergenic spacer (IGS), coding sequence (CDS), intron, IGS/CDS, and IGS/intron. IGS/CDS represents LDRs shared in IGS and CDS. IGS/intron represents LDRs shared in IGS and intron. (C) The frequency of LDRs in different genomic regions. 

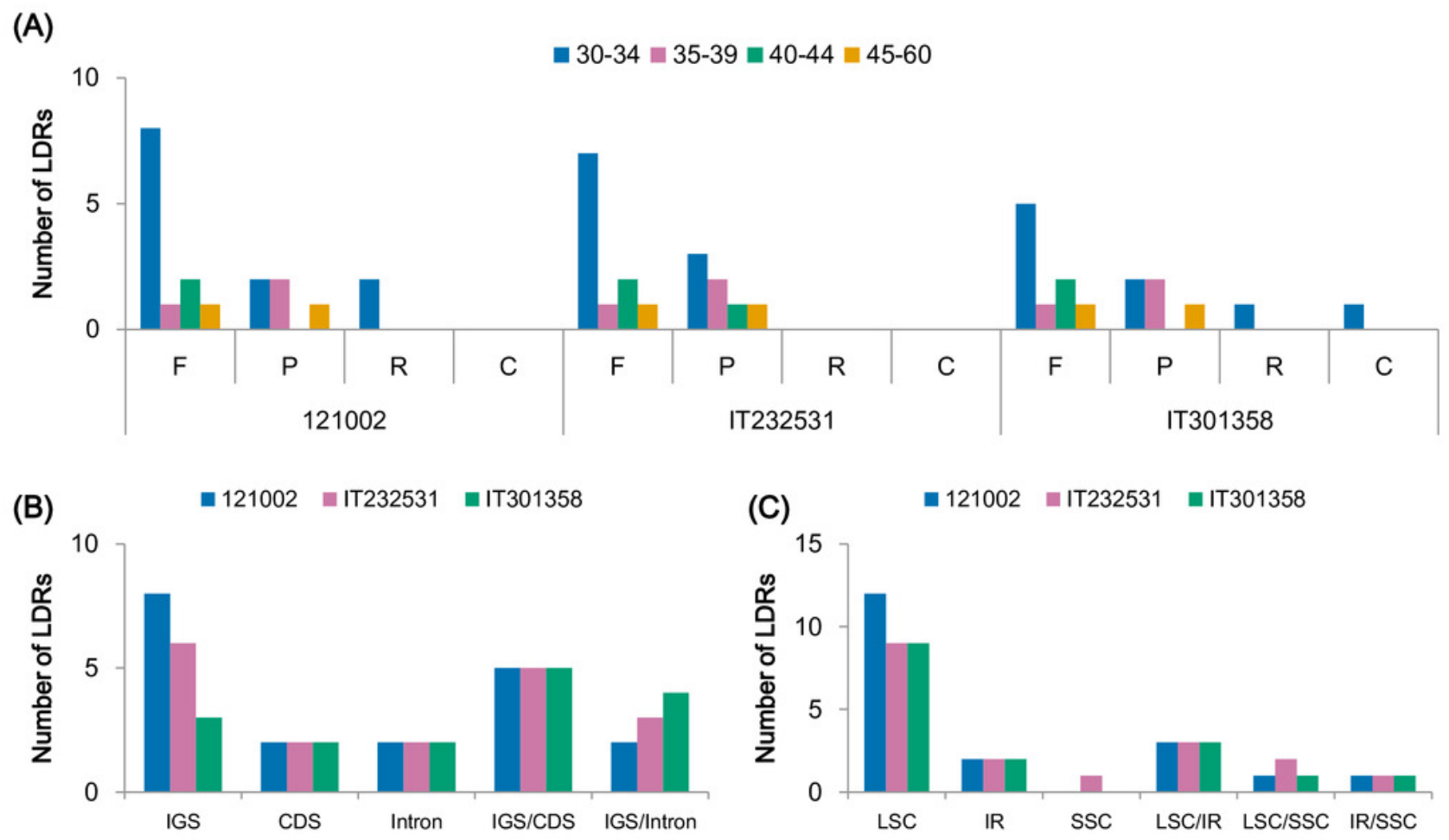
Figure 6

Cladograms using the maximum likelihood (ML) and Bayesian inference (BI) methods.

(A) ML tree based on the sequences of 77 shared protein-coding genes. (B) BI tree based on the sequences of 77 shared protein-coding genes. (C) ML tree based on the complete chloroplast genomes. (D) BI tree based on the complete chloroplast genomes. Numbers above the branches indicate bootstrap support values in ML trees and BI posterior probability in $\mathrm{BI}$ trees.

(A)

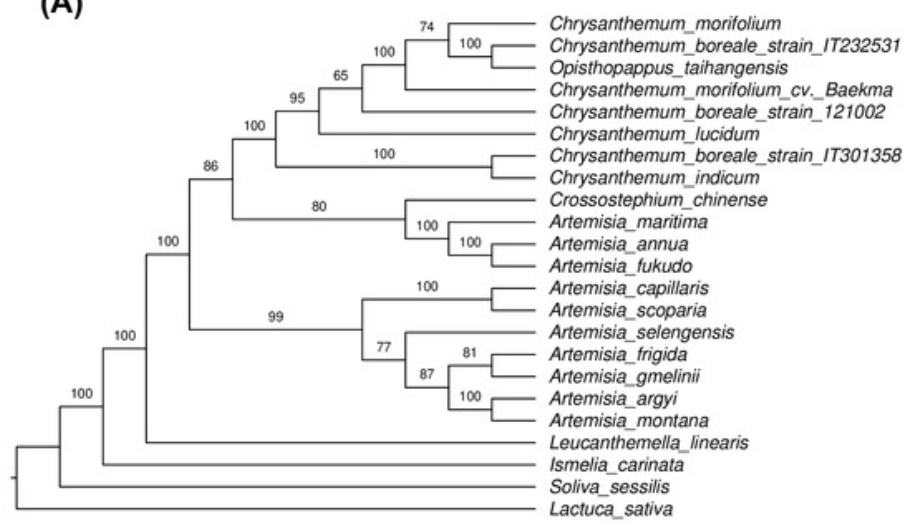

20

(C)

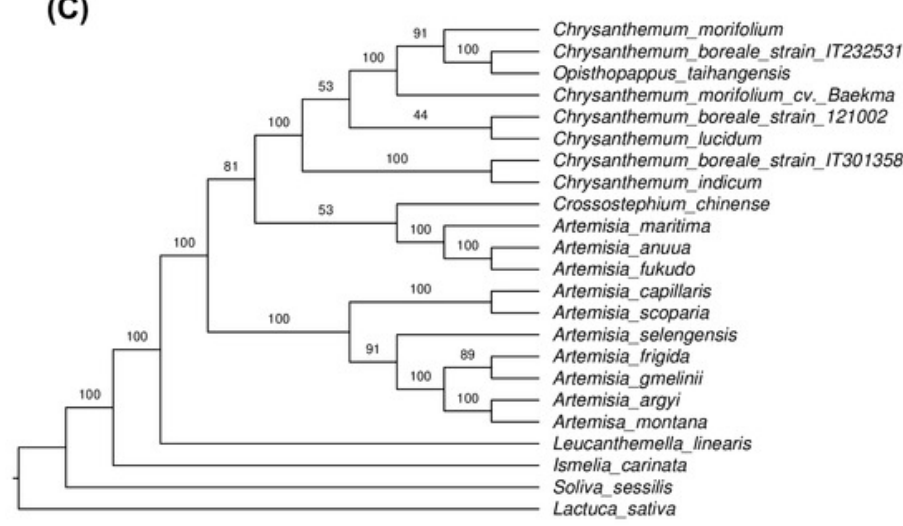

2.0
(B)
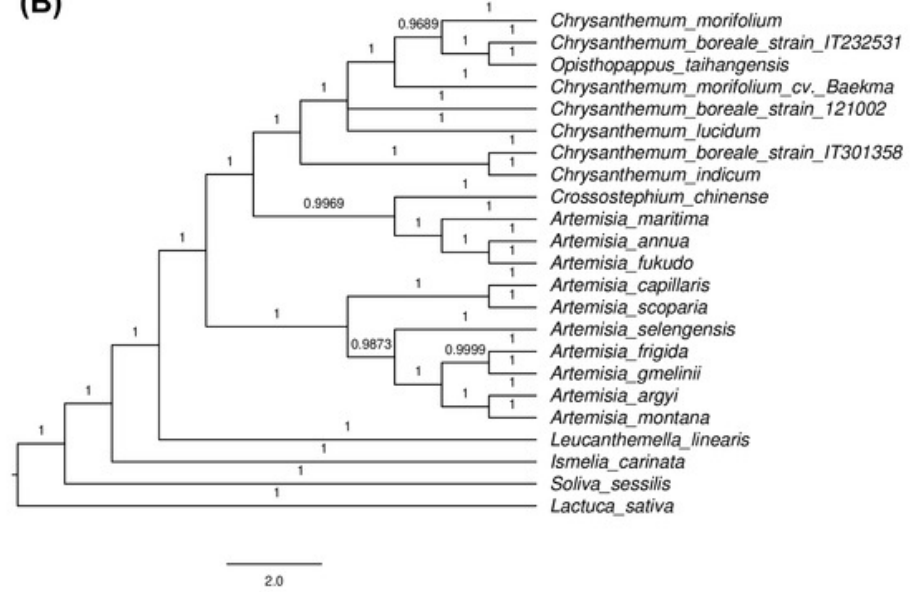

(D)

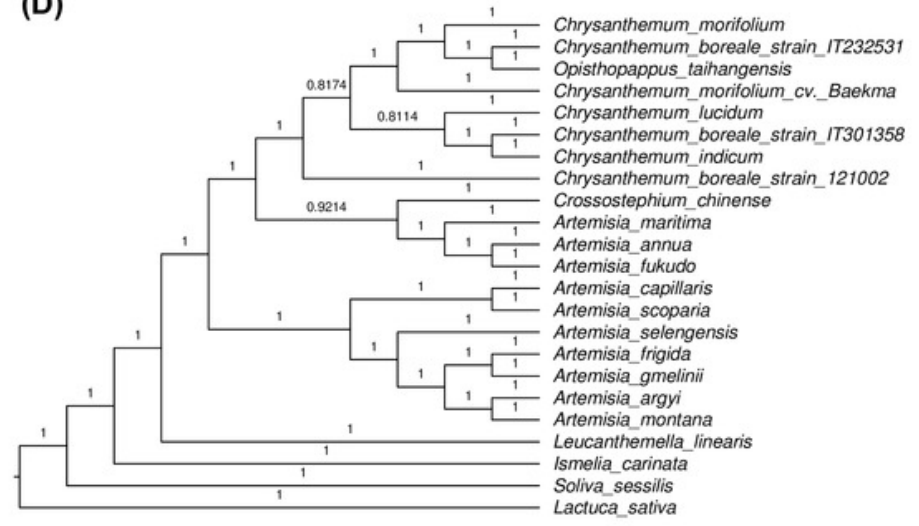




\section{Table $\mathbf{1}$ (on next page)}

Summary of complete chloroplast genomes of three Chrysanthemum boreale strains. 
1 Table 1. Summary of complete chloroplast genomes of three Chrysanthemum boreale strains.

\begin{tabular}{llll}
\hline Attributes & $\mathbf{1 2 1 0 0 2}$ & IT232531 & IT301358 \\
\hline Total size (bp) & 151,012 & 151,098 & 151,010 \\
LSC size (bp) & 82,817 & 82,880 & 82,788 \\
SSC size (bp) & 18,281 & 18,312 & 18,310 \\
IR size (bp) & 24,957 & 24,953 & 24,956 \\
Total GC content (\%) & 37.5 & 37.5 & 37.5 \\
LSC GC content (\%) & 35.6 & 35.5 & 35.6 \\
SSC GC content (\%) & 30.9 & 30.8 & 30.9 \\
IR GC content (\%) & 43.1 & 43.1 & 43.1 \\
Number of unique genes & 113 & 113 & 113 \\
Number of unique protein-coding genes & 80 & 80 & 80 \\
Number of unique tRNA genes & 29 & 29 & 29 \\
Number of unique rRNA genes & 4 & 4 & 4 \\
Genes duplicated & 17 & 17 & 17 \\
Genes with intron & 16 & 16 & 16 \\
Pseudogene & 1 & 1 & 1 \\
\hline
\end{tabular}

2 
Table 2 (on next page)

List of genes in the $C$. boreale chloroplast genomes. 
1 Table 2. List of genes in the $C$. boreale chloroplast genomes.

\begin{tabular}{|c|c|c|}
\hline Category & Group of genes & Name of genes \\
\hline \multirow[t]{5}{*}{ Self-replication } & Large subunit of ribosomal proteins & $r p l 2^{*}(2 \mathrm{x}), 14,16,20,22,23(2 \mathrm{x}), 32,33,36$ \\
\hline & Small subunit of ribosomal proteins & $\begin{array}{l}\operatorname{rps} 2,3,4,7(2 \mathrm{x}), 8,11,12^{* *}(2 \mathrm{x}), 14,15,16^{*}, 18 \\
19\end{array}$ \\
\hline & DNA dependent RNA polymerase & $\operatorname{rpo} A, B, C 1^{*}, C 2$ \\
\hline & rRNA genes & $\operatorname{rrn} 16(2 \mathrm{X}), \operatorname{rrn} 23(2 \mathrm{X}), r r n 4.5(2 \mathrm{X}), \operatorname{rrn} 5(2 \mathrm{X})$ \\
\hline & tRNA genes & $\begin{array}{l}\operatorname{trn} A-U G C^{*}(2 \mathrm{x}), \operatorname{trn} C-G C A, \quad \operatorname{trn} D-G U C, \quad \operatorname{trn} E- \\
U U C, \operatorname{trn} F-G A A, \operatorname{trn} M_{-}-C A U, \operatorname{trn} G-G C C, \operatorname{trn} H- \\
G U G, \operatorname{trn} I-C A U(2 \mathrm{x}), \operatorname{trn} I-G A U^{*}(2 \mathrm{x}), \operatorname{trn} K-U U U^{*}, \\
\operatorname{trn} L-C A A(2 \mathrm{x}), \operatorname{trn} L-U A A^{*}, \operatorname{trn} L-U A G, \operatorname{trn} M-C A U, \\
\operatorname{trn} N-G U U(2 \mathrm{x}), \operatorname{trn} P-U G G, \quad \operatorname{trn} Q-U U G, \quad \operatorname{trnR}- \\
A C G(2 \mathrm{x}), \operatorname{trn} R-U C U, \operatorname{trn} S-G C U, \operatorname{trn} S-G G A, \operatorname{trn} S- \\
U G A, \operatorname{trn} T-G G U, \operatorname{trn} T-U G U, \operatorname{trn} V-G A C(2 \mathrm{x}), \operatorname{trn} V- \\
U A C^{*}, \operatorname{trn} W-C C A, \operatorname{trn} Y-G U A\end{array}$ \\
\hline \multirow[t]{6}{*}{ Photosynthesis } & Photosystem I & $p s a A, B, C, I, J$ \\
\hline & Photosystem II & $p s b A, B, C, D, E, F, H, I, J, K, L, M, N, T, Z$ \\
\hline & NADH dehydrogenase & $n d h A^{*}, B^{*}(2 \mathrm{x}), C, D, E, F, G, H, I, J, K$ \\
\hline & Cytochrome b6/f complex & petA, $B^{*}, D^{*}, G, L, N$ \\
\hline & ATP synthase & $\operatorname{atp} A, B, E, F^{*}, H, I$ \\
\hline & Rubisco & $r b c L$ \\
\hline \multirow[t]{6}{*}{ Other genes } & Translational initiation factor & $\inf A$ \\
\hline & Maturase & $m a t K$ \\
\hline & Protease & $\operatorname{clp} P^{*}$ \\
\hline & Envelop membrane protein & cemA \\
\hline & Subunit Acetyl-CoA-Carboxylase & $a c c D$ \\
\hline & C type cytochrome synthesis gene & $\operatorname{ccs} A$ \\
\hline Unknown & Conserved open reading frame & $y c f 1,2(2 \mathrm{x}), 3^{*}, 4,15(2 \mathrm{x})$ \\
\hline
\end{tabular}

2 Note: Intron-containing genes are marked by an asterisk $\left(^{*}\right)$. Trans-spliced gene is marked by two

3 asterisks $(* *)$. The duplicated genes are shown with $(2 \mathrm{X})$ next to the gene name. 


\section{Table 3(on next page)}

Comparison of introns length of $C$. boreale strains in $\mathrm{cp}$ genome. 
1 Table 3. Comparison of introns length of C.boreale strains in $\mathrm{cp}$ genome.

\begin{tabular}{|c|c|c|c|c|c|c|}
\hline No. & Genes & Location & & 121002 & IT232531 & IT301358 \\
\hline 1 & atpF & LSC & & 699 & 699 & 699 \\
\hline \multirow[t]{2}{*}{2} & clpP & LSC & Intron1 & 608 & 609 & 611 \\
\hline & & & Intron2 & 800 & 797 & 797 \\
\hline 3 & $n d h A$ & $\mathrm{SSC}$ & & 1045 & 1069 & 1063 \\
\hline 4 & $n d h B$ & IR & & 670 & 670 & 670 \\
\hline 5 & petB & LSC & & 747 & 746 & 747 \\
\hline 6 & petD & LSC & & 675 & 675 & 675 \\
\hline 7 & rpl2 & LSC & & 662 & 662 & 662 \\
\hline 8 & rpoC1 & LSC & & 732 & 732 & 732 \\
\hline 9 & $\operatorname{rps} 12$ & IR & & 535 & 535 & 535 \\
\hline 10 & rps16 & LSC & & 881 & 892 & 887 \\
\hline \multirow[t]{2}{*}{11} & ycf3 & LSC & Intron 1 & 740 & 743 & 743 \\
\hline & & & Intron2 & 711 & 713 & 711 \\
\hline 12 & $\operatorname{trn} A-U G C$ & IR & & 812 & 812 & 812 \\
\hline 13 & $\operatorname{trnI-GAU}$ & IR & & 776 & 776 & 776 \\
\hline 14 & $\operatorname{trnK} K \boldsymbol{U} U U$ & LSC & & 2568 & 2575 & 2560 \\
\hline 15 & $\operatorname{trn} L-U A A$ & LSC & & 424 & 423 & 425 \\
\hline 16 & $\operatorname{trn} V-U A C$ & LSC & & 572 & 572 & 572 \\
\hline
\end{tabular}

2 